\title{
Sense and Self-Referentiality in Living Beings
}

\author{
Arno L. Goudsmit
}

Received: 30 November 2007 / Accepted: 16 June 2008 /

Published online: 19 December 2008

(C) Springer Science + Business Media B.V. 2008

\begin{abstract}
This contribution investigates the idea that an act of signification can be understood in terms of the self-referentiality that is typical of the biological organization. The capacity of a living being to interpret and appreciate its own environment can be understood as being grounded in its ability to perform selfreferential experiences. We may call this the living being's capacity of sense. In any act that generates sense, it is possible to distinguish a process of signification from its outcome, but such a distinction between logical levels inevitably demands an external observer's point of view. Hence, the concept of 'subjectivity' can be defined in terms of an absence of such distinction between logical levels. This absence is considered pivotal both for the self-referential organization of the living and for the generation of sense. A case example from the field of psychotherapy is added to illustrate the distinction as well as the non-distinction between logical levels of description.
\end{abstract}

Keywords Self-reference $\cdot$ Relational biology $\cdot$ Signification $\cdot$

Circular complementarity · Subjectivity

\section{Two Types of Complementarity}

Biosemiotics has been defined in terms of the production and the recognition of meaningful signs by living beings, as a legitimate domain of study at the interface of biology and semiotics. This conception reminds us of Pattee's ${ }^{1}$ concept of two complementary descriptive domains, a domain of 'laws' and a domain of 'constraints'. The former is a domain of causally determined natural processes and the latter is a domain of behaviors that follow particular rules, as if guided by some grammar.

${ }^{1}$ e.g. Pattee 1972.

A. L. Goudsmit $(\bowtie)$

Medical Dept., University of Maastricht, Postbus 616, 6200 MD Maastricht, Netherlands

e-mail: arno.goudsmit@HAG.unimaas.nl 
The complementarity of these domains implies that a description of a biological process in terms of laws cannot be reduced to a description in terms of constraints, and vice versa. However, this irreducibility itself does not enlighten us about how these two types of description can become related, intertwined or even entangled. It is a case of what von Weizsäcker ${ }^{2}$ called 'parallel complementarity'. 3

Bohr also recognized a tension between the definition of a concept and its actual usage for dealing with empirical information. The usage of a concept impedes a full detachment from it, and, conversely, the analysis of a concept impedes a full usage of it for observations in the mean time. ${ }^{4}$ The conceptual tools that we use as instruments for ordering our observations cannot be analyzed while being used. Von Weizsäcker ${ }^{5}$ calls this 'circular complementarity'.

The major difference with parallel complementarity is that two modes of description are not considered mutually complementing as in parallel complementarity. What we have here, instead, is an act (e.g. an act of observation) that is complementary to the description of itself, because it cannot be performed and described at the same time. Either we focus upon the act and describe it, or we perform the act and focus upon that to which the act pertains. This holds in particular for the study of interactions between a measuring device and the measured object, as in quantum mechanics. We, as investigators, cannot use the instrument and simultaneously observe its interactions. Eventually this is due to our position external to the instrument: we can either incorporate it as an extension of our body and use it for the measurement of some phenomenon, or we can detach from it and observe its interactions as phenomena in their own right; but we cannot do both at the same time.

The same holds for the usage of language, such as, for instance, the language game of classical (newtonian) causation. Either we use this language for the description of causal phenomena, or we investigate the concepts of causation that are implicit in our language; but in the latter case we cannot observe the causal phenomena as well. Following Bohr's train of thought with respect to language, this complementarity issue has been elaborated extensively in terms of 'linguistic complementarity' by Löfgren. ${ }^{6}$ His major tenet, inspired also by Gödel's work, is that a language cannot be completely described in the language itself: the ways in which descriptions are to be interpreted into actions and the ways in which actions are to be coded into descriptions cannot be fully grasped within one encompassing framework. I will use this result below in my discussion of self-reference in signification.

\section{Self-Referentiality}

Hierarchical series of logical levels have been the regular way, since Principia Mathematica, to avoid logical conflicts due to self-referential definitions and relations.

\footnotetext{
${ }^{2}$ Von Weizsäcker 1955, p. 522.

3 cf. Bohr 1934, p. 96.

${ }^{4}$ Bohr 1934, p. 20.

${ }^{5}$ Von Weizsäcker 1955, p. 524.

${ }^{6}$ Löfgren 1990.
} 
But, conversely, we may also use the notion of self-referentiality to arrive at a better understanding of these relations, especially of the relations implied in the act of signification by a living being.

\section{Self-Referentiality Within Biological Organizations}

There is a trend in biology named 'relational biology"7 in which the distinctive characteristic of life is believed to be a network of relationships between physical processes that has a self-referential closure of efficient causation.

This means that biological organizations are assumed to consist of a network of processes such that each process is triggered by another process, and so in a circular (closed) way. There is no 'first cause' within an organism. This is true also for those processes that are supposed to regulate other processes, such as enzymatic activities. These processes should be distinguishable from those of 'regular' metabolism and at the same time should be part of the same network of circular relations.

This is peculiar, because it means that regulative (enzymatic) processes are sometimes acting at a distinct level, and sometimes not. Or, put differently: within the living organization there are processes that can be described both in terms of a distinction and in terms of a non-distinction between logical levels. One of Rosen's (1991) major tenets is that, due to the self-referential organization of the living organization, it is not possible to construct one encompassing model for it. His argument is inspired by Gödel's work and shows an interesting parallel to Löfgren's point that a language cannot be fully self-descriptive. I will use these ideas in the following sections.

The reader may be reminded of Maturana and Varela's writings on autopoiesis. ${ }^{8}$ Indeed, the concept of autopoiesis is based upon the same concept of (networks of) self-referential relations between processes. However, both qua terminology, qua concepts and qua years of publication ${ }^{9}$, it is obvious that Rosen's (and Rashevsky's) writings were earlier and at least highly influential to the autopoiesis literature, even though references to Rosen's work are very sparse. ${ }^{10}$ Maturana and Varela did not elaborate a theory of experiences. Though Maturana ${ }^{11}$ coined the term 'emotioning', this term did not pertain to paradox or to the self-referentiality of performance. I have dealt extensively with Maturana's concepts of 'language', 'distinction' and 'coordination of action'. ${ }^{12}$ However, I did not find in the writings of Maturana and Varela a parallel or an analogy between the idea of autopoiesis (organizational closure in the living organism) on the one hand, and language as a biological phenomenon on the other. In that respect too, the work of Robert Rosen seemed to me to be more coherent. Accordingly, the description of a living being resembles the

\footnotetext{
${ }^{7}$ Rosen 1991. See also: Mikulecky 2007.

${ }^{8}$ Maturana and Varela 1980.

${ }^{9}$ See e.g. Rosen 1958.

${ }^{10}$ with a single exception in Varela 1979.

${ }^{11}$ Maturana 1988.

12 Goudsmit 1998.
} 
description of a natural language: both display relations and connections that cannot be reduced to an encompassing formal (syntactical) model. ${ }^{13}$

\section{Self-Referentiality Within Acts of Signification}

With respect to the domain of signs there is an extended body of literature that describes the self-referentiality of semiotic relationships. This parallels some descriptions by the great hermeneutic philosophers that deal with the actuality and situatedness of emotional reactions in living beings (esp. humans).

An interesting example of this can be found in Heidegger:

"What is phenomenologically decisive in the phenomenon of feeling is that it directly uncovers and makes accessible what is felt.... Feeling is having a feeling-for, and so much so that in it the feeling ego at the same time feels its own self", 14

This quotation nicely brings us to the core of self-referential experience: a feeling ego feels something as well as itself simultaneously. That is: there is no distinction between the object felt and the act of feeling that is instrumental to it; these are experienced as one and the same, and not as distinct things. From an external point of view we may understand this as a distinction that is not being made during an act of feeling. This distinction could have been made by someone else, but in actuality is not being made by the 'feeling ego' itself. This, I think, is crucial for our understanding of sense in general: it is the absence of this distinction, so that, due to this absence, a single act of sensation seems to contain and combine two things: the feeling of the object and the feeling of the feeling ego itself.

Here we find a complementarity of descriptive domains: the former 'feeling' can be described in terms of meanings; the latter 'feeling' can be described in terms of an event or process during which this meaning is constructed. Nevertheless, the 'feeling ego' feels them both at once. Accordingly, we may even come to understand the very notion of subjectivity as this kind of simultaneity that we can denote in terms of an absence of distinction between object perceived (or 'feeling-for') and process (or 'feeling ego').

Another example can be found in Peirce's ideas on the concept of sign. Peirce writes:

"the sign not only determines the interpretant to represent $[\ldots]$ the object, but

also determines the interpretant to represent [...] how this very sign itself represents that object". 15

Here we also find the 'sign' qualified in terms of the same type of double role, as in Heidegger's quotation. For the sign is here seen to be both a way to arrive at a representation of the object and a way to represent this representing relation between sign and object.

\footnotetext{
${ }^{13}$ Goudsmit 2007.

${ }^{14}$ Heidegger 1982.

${ }^{15}$ Peirce 1998 (reference due to E. Fernandez).
} 
Eliseo Fernandez put it thus:

"As we know, in Peircean semiotics the sign is defined as a representamen in terms of its capacity to determine another sign, its interpretant, to represent an object. In Peirce's mature semiotic theory he emphasized that the interpretant, besides representing the object, must at the same time represent the very relation of representation which the sign has to that object."16

Accordingly, the interpretant is supposed to contain simultaneously both the object and the relation between sign and object. The latter is instrumental to the former and hence the two cannot be described at the same logical level. But they are supposed to be performed simultaneously!

Thus, there is an entanglement of logical levels of description implicit in these descriptions of 'feeling' and 'sign' respectively. Both 'sign' and 'feeling' are seen to perform a double task, the constituent tasks of which do not fit into one encompassing description.

\section{Signification and the Living Organization}

Meaning assignment in computer languages is not comparable to signification by living beings. In the description of signification there is a moment of subjectivity that is totally lacking in machines. If a behavior can be described in strictly observational terms, without any logical levels of description becoming indistinct or popping up, then we are dealing with a machine, for its logic can be described in terms of a single encompassing model, and phrased in a context-free language. Accordingly, such behavior can be computed, unlike the living behaviors that require context dependent descriptions and that for that reason are of necessity not interpretable without ambiguities.

More specifically, with respect to acts of signification we may argue that a major criterion for the livingness of an entity that performs a signification consists of the absence (and impossibility) of such encompassing description. Instead, an observer must take recourse to partial descriptions.

Basically, one of those partial descriptions will be concerned with the content of the signification: what meaning is being assigned to what object? At the next higher level another description will focus on the processes of the meaning assignment, with principal questions such as: how is the meaning constructed? which experiences underlie this meaning? by which physical or other interactions is the subject/actor affected by the object?

Descriptions like these may be considered 'objective'. Typical is that the more objective they are, the less they represent the sense that is existing for the living being under study. This sense can be believed to be 'subjective', as it differs from the 'objective' points of view. More particularly, this 'subjectivity' has properties of a magic word, for it stands for the accomplishment of an integration between events that can be described objectively only by complementary descriptions.

Thus, in the experience of sense an indistinguishability is obtained between what an external observer might distinguish in terms of different logical types: form and

\footnotetext{
${ }^{16}$ E. Fernandez, 7th Gathering in Biosemiotics, Groningen.
} 
content, or process and outcome, or subject and instrument. This indistinguishability is constitutive for the subjectivity. That is, in order to understand an event of 'sense' it is necessary to suspend the distinction of logical types, to put this distinction between brackets; conversely, it is this latter distinction that characterizes the externality of an observer's position. This externality is characterized by descriptions that are based upon logical types. Suspending these logical types is an act that cannot be regulated or prescribed by these same descriptions! Hence, the 'subjective' is often considered as a domain beyond the scope of logic and rationality. But it is only beyond the scope of a logical typology that fully depends on the absence of selfreferentiality and paradox!

In the act of signification the object perceived coincides with the process of interaction between the subject and the object! The sign stands for the object and for its relation between sign and object; the feeling ego, as Heidegger put it, feels itself as well as the object of its attention. The sense that is experienced is the encounter with the world. This, indeed, is hard stuff for computationalists, but it is obvious for poets. The experience of sense integrates the person's experience of the object as one that coincides with the way in which it is perceived. I have called the latter type of object 'naive objects'. 17

\section{Sense}

The capacity of a living being to interpret and appreciate its own environment can be understood as being grounded in its ability to perform self-referential experiences. We may call this the living being's capacity of sense. Sense is self-referential in that it requires the living being's organization as a substrate for the construction of meaning that is to be assigned to the environment (cf Dreyfus 2007). This sense remains unaccessible for an external observer, as long as he keeps the logical levels strictly distinct. Thus the difference between 'subjective' and 'objective' perceptions is situated in the way in which logical levels are dealt with. Our position is therefore radically different from the traditional, neo-kantian, notion that subjective perception is based upon an 'interpretation' or 'experience' of some objective reality!

I will now illustrate my point with a case example.

\section{Case Example: A Trauma}

The following case has been derived from my work as a psychotherapist. Personal data have been omitted or changed for obvious reasons.

A man complains about his employer's recent decision to move his work section to another building. This is a painful change, and the more so because it will invalidate lots of efforts the man has made to adjust to the current work environment. Talking about his complaints, we find out that the foreseen change bears the

\footnotetext{
${ }^{17}$ Goudsmit 1998. The term 'naive' is used in contrast to 'critical'. Naive objects are a kind of poetic images in which a critical (kantian) distinction between 'being' and 'knowing' is absent. Vico's 'imaginative universals' can be recognized as a classical instance of these (cf. Verene 1981). Also Gadamer's (1960, pp. $111 / 2$ ) notion of 'aesthetic non-distinction' is closely related.
} 
connotation of being overpowered, especially by the employer's soothing accounts that were brought into circulation in order to reassure the employees.

At this moment in the conversation, the therapist is making a distinction between the move itself and the sense of being overpowered. Taking the latter as a lead, we found that this feeling was also remembered from an occasion in his childhood, when he was not told that a dear cousin had died in a car accident. Instead, he had been told some inadequate stories that were apparently meant not to make him worry. The trauma, therefore, consists of the early experience of being comforted for false reasons, so that efforts to comfort him became first of all alarm signals.

Now a first therapeutic attempt to relieve the impacts of the early trauma may seem to consist in helping the patient to make a distinction between the current situation at work and the early situation at home. Here it is the absence of a distinction that can be taken as the problem, so that the employer's soothing narratives get their ominous connotation. Furthermore, this very absence was crucial for these narratives to obtain their alarming qualities.

The self-referentiality that is involved here consists of the man's painful experiences as occurring in a double role: both as a mode of perceiving and interpreting his experiences and as the object of these perceptions/interpretations. The danger perceived is what I called a 'naive object'. The early experiences can have their traumatic impact only by having become indistinguishable to the current ones. This, however, is not a matter of diminished intelligence. It is how the organism is made up: through and by referring to itself it can refer to the environment. Only when a split between 'now' and 'then' is enforced, can a distinction be constructed between 'facts' and 'assigned meanings', as if these existed in two disjoint ontological domains! The point is that the distinction between 'fact' and 'meaning' is constructed, not pre-existent. A therapy that goes along lines like these is usually classified as 'cognitive psychotherapy'.

Now what if the distinction between 'now' and 'then' does not give the desired relief? This is where cognitive therapy may not have enough to offer. It is here that a more 'experiential' and 'dynamic' style of psychotherapy can be taken recourse to. Then it is no longer about the distinction between 'now' and 'then', however well it may have been understood intellectually by the patient. Instead, therapy has to enter into the signification itself, so that the traumatic experience itself becomes accessible as an event in which the patient's distrustfulness is indistinguishable from the distrusted events (both those in the past and in present). Psychotherapeutic jargons usually do not express any reference to logical levels of description, but denote this indistinguishability in terms such as 'actualization', 'transference', 'reenactment', 'corrective experience'.

Basically, however, each of these terms refers to some kind of reconstruction of the non-distinction between the mode (or process) of experience and the content (or object) experienced. In the course of this reconstruction the patient's sense (distrust) becomes accessible. Contrary to being dissected into components of 'meaning' versus 'fact', it is encouraged to enter into the scene, to be 'staged' and brought into existence as a naive object. Then if new solutions can be found by the patient, it will be due to the circumstance that the sense that is experienced is being recognized as real, so that real coping can be looked for and tried. Various techniques are available here, but these are beyond the scope of the present paper. 


\section{In Conclusion}

I discussed self-referential relations within the living organization as a substrate for self-referential relations in the act of signification. More particularly, the usage of signs can be seen to be a function of the living being in order to create constancy by not distinguishing experiences from the processes that generate them.

\section{References}

Bohr, N. (1934). The quantum of action and the description of nature. In N. Bohr (Ed.), Atomic theory and the description of nature. Cambridge: Cambridge U.P.

Dreyfus, H. L. (2007). Why Heideggerian AI failed an how fixing it would require making it more Heideggerian. Philosophical Psychology, 20(2), 247-268.

Gadamer, H. G. (1960). Wahrheit und methode. Grundzüge einer philosophischen Hermeneutik. Tübingen: Mohr.

Goudsmit, A. L. (1998). Towards a negative understanding of psychotherapy. Doctoral thesis. University of Groningen. Available at: http://dissertations.ub.rug.nl/faculties/ppsw/1998/a.1.goudsmit/.

Goudsmit, A. L. (2007). Some reflections on Rosen's conceptions of semantics and finality. Chemistry and Biodiversity, 4(10), 2427-2435.

Heidegger, M. (1982). Die grundprobleme der phänomenologie (summer semester 1927). Translated as The Basic Problems of Phenomenology by Albert Hofstadter. Bloomington: Indiana University Press.

Löfgren, L. (1990). The partiality of self-reference. In F. Heylighen, E. Rosseel, \& F. Demeyere (Eds.), Self-steering and cognition in complex systems. Toward a new cybernetics. New York: Gordon \& Breach.

Maturana, H. R. (1988). Reality: the search for objectivity or the quest for a compelling argument. Irish Journal of Psychology, 9(1), 25-82.

Maturana, H. R., \& Varela, F. J. (1980). Autopoiesis: the organization of the living (orig. 1973). In Autopoiesis and cognition: the realization of the living. Boston/Dordrecht: Reidel.

Mikulecky, D. (ed.). (2007). System Theory and Biocomplexity (Commemorative Issue, Robert Rosen). Chemistry and Biodiversity, 4, 10.

Pattee, H. H. (1972). Laws and constraints, symbols and languages. In C. H. Waddington (Ed.), Towards a theoretical biology(vol. vol. 4). Edinburgh: Edinburgh University Press.

Peirce, C. S. (1998). The essential peirce: Selected philosophical writings. Volume 2 (1893-1913). Ed. Peirce Edition Project. Bloomington \& Indianapolis: Indiana University Press.

Rosen, R. (1958). A relational theory of biological systems. Bulletin of mathematical biophysics, 20, $245-260$.

Rosen, R. (1991). Life itself. A comprehensive inquiry into the nature, origin and fabrication of life. New York: Columbia Univ. Press.

Varela, F. J. (1979). Principles of biological autonomy. New York: North-holland.

Verene, D. P. (1981). Vico's science of imagination. Ithaca/London: Cornell U.P.

Von Weizsäcker, C. F. (1955). Komplementarität und Logik. Die Naturwissenschaften, 42, 521-529, 546-555. 